\title{
Functional characterization of human 1-acylglycerol-3-phosphate- $O$ - acyltransferase isoform 9: cloning, tissue distribution, gene structure, and enzymatic activity
}

\author{
Anil K Agarwal, Suja Sukumaran, Rene Bartz ${ }^{1}$, Robert I Barnes ${ }^{2}$ and Abhimanyu Garg \\ Division of Nutrition and Metabolic Diseases, Department of Internal Medicine, Center for Human Nutrition, University of Texas Southwestern Medical Center, \\ 5323 Harry Hines Boulevard, Dallas, Texas 75390 USA \\ ${ }^{1}$ Department of Cell Biology and ${ }^{2}$ McDermott Center for Human Growth and Development, University of Texas Southwestern Medical Center, 5323 Harry Hines \\ Boulevard, Dallas, Texas 75390, USA \\ (Requests for offprints should be addressed to A K Agarwal; Email: anil.agarwal@utsouthwestern.edu)
}

\begin{abstract}
Most cells synthesize their glycerophospholipids and triglycerides (TG) to maintain the cellular integrity and to provide energy for cellular functions. The phospholipids are synthesized de novo in cells through an evolutionary conserved process involving serial acylations of glycerol-3-phosphate. Several isoforms of the enzyme 1-acylglycerol-3-phosphateO-acyltransferase (AGPAT) acylate lysophosphatidic acid at the $s n-2$ position to produce phosphatidic acid. We cloned a cDNA predicted to be an AGPAT isoform and designated it AGPAT9. The human AGPAT9 gene spans across 14 exons and encodes for a polypeptide of 534 amino acids. AGPAT9 is highly expressed in the lung and spleen, followed by leukocyte, omental adipose tissue, and placenta. In the Chinese Hamster Ovary (CHO), cell lysates overexpressing AGPAT9, we observed AGPAT activity but not the lysophosphatidylcholine acyltransferase activity. When AGPAT9 is coexpressed with
\end{abstract}

AGPAT1 in CHO cells, both the isoforms localize to the endoplasmic reticulum (ER) and occupy the same ER domain as AGPAT1. Despite substitution of asparagine with proline in the $\mathrm{NHX}_{4} \mathrm{D}$ motif and arginine with cysteine in the EGTR motif, AGPAT9 retains AGPAT activity suggesting that residues asparagine and arginine in the $\mathrm{NHX}_{4} \mathrm{D}$ and EGTR motifs respectively are not essential for the enzymatic activity. Based on the X-ray crystallographic structure of a related acyltransferase, squash gpat, a model is proposed in which a hydrophobic pocket in AGPAT9 accommodates fatty acyl chains of both substrates in an orientation, whereas the $\mathrm{HX}_{4} \mathrm{D}$ motif participates in catalysis. Based on the activity and expression pattern of AGPAT9 in the lung and spleen, this novel isoform could be implicated in the biosynthesis of phospholipids and TG in these tissues.

Journal of Endocrinology (2007) 193, 445-457

\section{Introduction}

Glycerophospholipids and triglycerides (TG) constitute an important pool of phospholipids and neutral lipids, involved in several cellular functions. For example, phosphatidic acid (PA) and phosphatidyl inositol are involved in signal transduction; phosphatidylethanolamine and phosphatidylserine in membrane integrity and TG in storing energy. Intracellular requirements of these phospholipids and TG are met by the de novo biosynthesis through several pathways (Coleman \& Lee 2004, McMaster \& Jackson 2004). Among these, the more widely studied pathway involves generation of phospholipids and TG from glycerol-3-phosphate. In this pathway, there is sequential esterification of the glycerol chain catalyzed by a variety of acyltransferases. The initial esterification at the $s n-1$ position of glycerol-3-phosphate is catalyzed by glycerol-3-phosphate acyltransferases (GPATs), followed by esterification at the $s n-2$ position by 1-acylglycerol-3-phosphate-O-acyltransferases (AGPATs, also known as lysophosphatidic acid acyltransferase (LPAAT)) and finally at the $s n-3$ position by diacylglycerol acyltransferases (Agarwal \& Garg 2003). The other members of the acyltransferase family include enzymes involved in acylation of proteins (palmitoyl acyltransferase) transferring fatty acid to amino acids or glyceronephosphate-O-acyltransferase (Webber \& Hajra 1993).

Recently, through positional cloning, we discovered that mutations in AGPAT2 cause congenital generalized lipodystrophy (CGL; Agarwal et al. 2002, Agarwal \& Garg 2003), a syndrome with almost complete loss of adipose tissue and predisposition to develop diabetes, hepatic steatosis, and hyperlipidemia (Garg 2004). Besides AGPAT2, there are seven other known isoforms, each of which is encoded by independent genes (Leung 2001, Li et al. 2003, Ye et al. 2005, Agarwal et al. 2006). A multiple sequence alignment of these eight known AGPAT isoforms indicates that several are duplicated, suggesting that several AGPATs are still to be discovered. Furthermore, given the availability of numerous structurally distinct lysophosphatidic 
acids (LPAs) and fatty acids for acylation intracellularly, we hypothesized that there could be additional AGPAT isoforms which still remain to be identified. These new AGPAT isoforms may differ in substrate specificity, i.e. may prefer specific LPAs and specific fatty acids for $s n-2$ acylation to perform distinct cellular functions. With the sequencing of the human and mouse genomes and the bioinformatics tools available, we cloned and characterized an additional AGPAT isoform encoding human AGPAT9. This isoform retains AGPAT activity very similar to another isoform AGPAT2.

\section{Materials and Methods}

\section{Bioinformatics}

The National Center for Biotechnology Information (NCBI) and Celera databases were used for the sequence analysis. Multiple protein alignment and phylogenetic tree were created using Vector NTi suites (InforMax, Bethesda, MD, USA).

\section{Cloning of human AGPAT9}

The search for additional gene encoding for an acyltransferase was performed by homolog comparison with known acyltransferases deposited in the various databases including NCBI, Celera and expressed sequence tags (ESTs). One of the hits, AK090444, showed significant homology to the known acyltransferases, including the conserved motifs, suggesting that this sequence may have the acyltransferase activity.

\section{Amplification of human AGPAT9 cDNA}

To determine if the sequences are expressed in human tissues, we initially designed primers 1 and 2 (Table 1) within the coding region to amplify the mRNA from the adipose tissue. The amplified PCR product was purified and the sequence was found to be identical to the predicted open reading frame (ORF).

Table 1 Primers for human AGPAT9 cDNA amplification with restriction sites underlined

\section{$5^{\prime}-3^{\prime}$ primer sequences}

\begin{tabular}{ll} 
Primer \# & \\
1 & GCCATCCCTGTGACCATGACGAT \\
2 & ATACAGCGCGGGGTTCCTCTTCT \\
3 & CGCACCATGTGGTTCGCCGGCGGCTT \\
4 & AGTCAGTCACGGAGACACCCAAGGC \\
5 & GCCTTGGGTGTCTCCGTGACTGACT \\
6 & CAGACGTCACTCGCAAAGAAGCTCA \\
7 & CGAGACCCGCGCCCAGCTAG \\
8 & CGGGATCCATGCGCACCATGTGGTTCGCCGG \\
9 & GGACTGCGCCCGTCTCTTGA \\
10 & CGCTCGAGCTAATCCAGCTTCTTGCGAACAGG \\
11 & CGGGATCCATGAGGCTGCGGGGAGGATGCGGAC \\
12 & CGCTCGAGATGAGGCTGCGGGGAGGATGCGGAC \\
13 & CGGGATCCATCCAGCTTCTTGCGAACAGGCTTC \\
\hline
\end{tabular}

To amplify the entire ORF, additional primers were then designed in the $5^{\prime}$ and $3^{\prime}$ untranslated regions and amplified in two overlapping fragments using primer pairs 3 and 4 , and primer pairs 5 and 6 (Table 1) and the human adipose tissue Marathon Ready cDNA (Clontech). The PCR products were gel purified and sequenced directly using the amplification primers and cloned in TA cloning vector (pCR2.1; Invitrogen). These overlapping PCR fragments were then combined and reamplified using only the $5^{\prime}$ and $3^{\prime}$ flanking primer pairs 3 and 6 (Table 1 ). The PCR product was gel purified and cloned in pDrive vector (Qiagen) for further sequencing and cloning steps.

Generation of wild-type AGPAT9 expression vector (short form)

To construct the AGPAT9 expression plasmid, the pDriveAGPAT9 was used as the template and primer pair designed to only amplify the ORF (primers 8 and 10; Table 1). The restriction sites BamHI and XhoI were incorporated into the primers for ease in subsequent cloning into the mammalian expression vector; pcDNA3.1(+)neo. The amplified product and the vector were digested with XhoI and BamHI and ligated to the same sites. The expression plasmid was restricted with appropriate enzymes to ascertain the orientation of the insert in relation to the promoter. This expression plasmid was named as pAGPAT9-SF.

\section{Generation of wild-type AGPAT9 expression vector (long form)}

Initially, we amplified and generated mammalian expression construct based on available nucleotide sequences (GenBank entry AK090444), however, on further alignment of human AGPAT9 protein with homologous protein sequences from several other species revealed that there are additional amino terminal protein sequences which were missed in the human. Based on this information, we amplified these $5^{\prime}$-sequences such that an overlapping fragment with the short form of AGPAT9 was generated using primer pairs 7 and 9 (Table 1). The generation of the mammalian expression plasmid was the same as for the short form except primer pairs 10 and 11 (Table 1). This expression plasmid was named as pAGPAT9-LF.

Generation of V5-epitope-tagged wild-type AGPAT9 expression vector (long form)

The construction strategy for the V5 epitope tagged AGPAT9 expression vector was the same as described above, except the AGPAT9-LF was amplified with primer containing the V5 epitope sequences with the removal of the first ATG of the AGPAT9 protein (in order to remove the spurious protein translation). (5'-CGGGATCCATGGGTAAGCCTATCCCTAACCCTCTCCTCGGTCTCGATTCTACGAGGCTGCGGGGATGCGGACCCCG- $3^{\prime}$; the BamHI restriction site is in bold and the V5 epitope is underlined) and the primer 10 (Table 1). 
Generation of EGFP-tagged wild-type AGPAT9 expression vector (long form)

The construction of the wild-type fusion protein with GFP was carried out using the AGPAT9 wild-type plasmid as the template and primer pairs 12 and 13 (Table 1). The amplified product and the plasmid pEGFP-N3 (Clontech) were restricted with XhoI and BamHI and cloned in the similar site. The expression plasmid was sequenced to ascertain the orientation and the correctness for the junction sequences. The human AGPAT1-REP was generated by excising the AGPAT1 coding region from the pDrive-hAGPAT1 (unpublished) to the KpnI and XhoI and cloning in the compatible restriction site of expression vector dsRed-T4-N1 (Clontech).

\section{Genomic localization of human AGPAT9 and gene structure}

The human cDNA for AGPAT9 was blasted against the genomic databases (NCBI) which identified the gene located on chromosome 5p15.5 (contig: NT_006576.15, nt $1526408-1426586$ and Hs5_6733, nt $1589408-$ $1489586)$.

\section{Northern blot analysis}

To determine the tissue expression pattern and transcript size, a multiple tissue total RNA blot was obtained from Clontech and was hybridized with the probe generated with primer pairs 5 and 6 (274 bp fragment). Briefly, the blot was hybridized with ${ }^{32} \mathrm{P}-$ labeled probe generated from the above fragment overnight at $60^{\circ} \mathrm{C}$. The blot was washed with decreasing concentration of sodium salt at $65^{\circ} \mathrm{C}$. The final wash was at $0 \cdot 1 \times$ SSC; $0 \cdot 1 \%$ SDS for $30 \mathrm{~min}$ at $65^{\circ} \mathrm{C}$. The blot was exposed either overnight or for 7 days at $-80^{\circ} \mathrm{C}$. The blot was stripped and reprobed with the $\beta$-actin probe as a control as suggested by the manufacturer. The scanned images were quantified using LabWorks 4.0 software (UVP Inc., Upland, CA, USA).

\section{Quantitative real-time PCR in human tissue panel}

Quantitative PCR was performed using the TaqMan primer and probes, designed using primer express software, ABI PRISM 7700 sequence detection system and primer express analysis software (Livak 1997; ABI user bulletin 2). The human cDNA panel was from Clontech. Briefly, 100 pg cDNA was added to the forward (5'-TCGCTGACTTCCACAGGTTTG-3') and reverse ( $5^{\prime}$-GGTGAGGTCTCTGCACAGCTTT- $3^{\prime}$ ) primers along with fam-labeled probe (AATACCTGTACCCGGATCA) and universal mix containing AmpliTaq and appropriate buffers. The PCR was followed for 40 cycles of $94^{\circ} \mathrm{C}$ for $15 \mathrm{~s}$ and $60^{\circ} \mathrm{C}$ for $30 \mathrm{~s}$. The cDNA was amplified in duplicate with G3PDH as an internal control. The $\Delta C_{\mathrm{t}}$ value for each tissue was calculated as $\Delta C_{\mathrm{t}}=$ $\left(C_{\mathrm{t}}\right.$ (tissue) $\left.-C_{\mathrm{t}}(\mathrm{G} 3 \mathrm{PDH})\right)$.
Generation of stably expressing wild-type AGPAT9 in Chinese Hamster Ovary (CHO) cells

The CHO cells stably expressing AGPAT9 were generated as described earlier (Haque et al. 2005). Stable-transfected $\mathrm{CHO}$ cell lines were selected in $500 \mu \mathrm{g} / \mathrm{ml} \mathrm{G418} \mathrm{(Sigma).} \mathrm{The} \mathrm{G418} \mathrm{resistant} \mathrm{cells} \mathrm{in}$ each well were scored as a single pool. Such pools were expanded for further studies. Cells transfected with pcDNA $3.1(+)$ vector alone were used as controls. The heterologous expression of human AGPAT9 was verified by reverse-transcriptase polymerase chain reaction (RT-PCR) as described before.

\section{AGPAT enzymatic activity of AGPAT9 in the cell lysate}

Three to four independent pools of cells were expanded after selection in G418. The cells were plated in $60 \mathrm{~mm}$ dishes and grown to confluence. The medium was then removed and the cells were rinsed twice with PBS and harvested by scraping in $200 \mu \mathrm{l}$ of $20 \mathrm{mM}$ Tris- $\mathrm{HCl}(\mathrm{pH} \mathrm{7 \cdot 5)}$ and $5 \mathrm{mM} \mathrm{NaCl}$ containing protease inhibitor cocktail (Roche). Cells were subjected to a single freeze thaw step and then sonicated three times with $7 \mathrm{~s}$ burst, followed by a $1 \mathrm{~min}$ cooling on ice (Vibracell High Intensity Ultrasonic Liquid Processor; Sonics \& Materials Inc., Newtown, CT, USA). Cellular debris and nuclei were removed by centrifugation $(1000 \mathrm{~g}$ for $10 \mathrm{~min}$ at $4{ }^{\circ} \mathrm{C}$ ), and the post nuclear supernatant was used for the enzymatic activity. Protein concentration was determined by a commercially available colorimetric assay (Bio-Rad Laboratories).

The enzyme activity was determined by measuring the conversion of $\left[{ }^{3} \mathrm{H}\right] \mathrm{LPA}$ to $\left[{ }^{3} \mathrm{H}\right] \mathrm{PA}$ as described previously (Haque et al. 2005, Agarwal et al. 2006). Briefly, the enzymatic reaction was assembled in $200 \mu \mathrm{l}$ of $100 \mathrm{mM}$ Tris-HCl (pH 7.4), containing the following: $10 \mu \mathrm{mol} / 1$ LPA (oleoyl-sn-1-glycerol-3-phosphate, Avanti Polar Lipids, Alabaster, AL, USA), $50 \mu \mathrm{mol} / 1$ oleoyl CoA (Sigma), $1 \mu 1$ $\left[{ }^{3} \mathrm{H}\right]$ oleoyl-LPA (specific activity $30-60 \mathrm{Ci} / \mathrm{mmol}$; PerkinElmer Life and Analytic Sciences, Boston, MA, USA), and $1 \mathrm{mg} / \mathrm{ml}$ fatty acid free bovine serum albumin. The reaction was started by adding $20 \mu \mathrm{g}$ cell lysate followed by incubation for $10 \mathrm{~min}$ at $37^{\circ} \mathrm{C}$. The reaction was terminated by adding $0.5 \mathrm{ml} 1$-butanol containing $1 \mathrm{~N}-\mathrm{HCl}$ and to extract phospholipids. The butanol extract was dried under vacuum and the LPA and PA were resolved using the solvent system chloroform-methanol-acetic acidwater (25:10:3:1). Radioactive spots were identified by comigration with unlabeled LPA and PA standard and visualized in iodine vapors. The $\left[{ }^{3} \mathrm{H}\right] \mathrm{LPA}$ and $\left[{ }^{3} \mathrm{H}\right] \mathrm{PA}$ spots were scraped and counted for radioactivity (Tri-Carb Liquid Scintillation Counter 3100TR; Perkin-Elmer Life Sciences). The enzyme activity of each cell pool were determined as described before (Haque et al. 2005, Agarwal et al. 2006). 
Lysophosphatidylcholine acyltransferase (LPCAT1) enzymatic activity of AGPAT9-LF in the cell lysate and tissue homogenate

LPCAT1 activity in cell lysate was determined as described previously (Chen et al. 2006, Nakanishi et al. 2006). Cell lysates were obtained from the V5-tagged expressing cells and incubated with $\left[{ }^{14} \mathrm{C}\right]$ palmitoyl lysophosphatidylcholine in the presence of palmitoyl-CoA. The incubation was terminated by adding chloroform: methanol $(2: 1 \mathrm{v} / \mathrm{v})$ mixture. Organic phase was dried and resolved on thin layer chromatography (TLC) using solvent system chloroform:methanol:acetic acid:water (50:25:8:4 v/v). Bands corresponding to standard LPC and PC were visualized by iodine, eluted, and quantitated. The tissue homogenate was prepared in the same buffer as for (AGPAT) assay, centrifuged to remove cell debris, and assayed using $20 \mu \mathrm{g}$ total protein.

\section{Acyl-CoA specificity}

specificity of esterification of $s n-2$ position of $\left[{ }^{3} \mathrm{H}\right] \mathrm{LPA}$ (sn-1-oleoyl-2-hydroxy-sn-glycerol-3-phosphate) was determined by substituting the fatty acids with the following acyl-CoAs. Decanoyl (C10:0)-, lauroyl (C12:0)-, myristoyl (C14:0)-, palmitoyl (C16:0)-, stearoyl (C18:0)-, oleoyl (C18:1)-, linolenoyl (C18:3; $n-3)-, \gamma$-linolenoyl (C18:3; $n-$ 6)-, arachidoyl (C20:0)-, arachidonoyl (C20:4;n-6)-, behenoyl (C22:0)-, docosahexaenoyl (C22:6;n-3)-, tricosanoyl (C23:0)-, ligneceroyl (C24:0)-, nervonoyl (C24:1;n-9)-, and hexacosanoyl (C26:0)-CoA. The assay conditions remain the same as described for the acyltransferase activity.

\section{sn-1-acyl-lysophosphaditic acid specificity}

To determine the specificity of various LPAs for the enzymatic activity, the following LPAs with various fatty acids at $s n-1$ position were used for the assay. Myristoyl (C14:0)-, palmitoyl (C16:0)-oleoyl (C18:1), arachidonoyl (C20:4)-, arachidoyl (C20:0)-, linoleoyl (C18:2)- and linolenoyl (C18:3). The enzymatic assay was assembled as before except that unlabeled LPAs and $\left[{ }^{14} \mathrm{C}\right]$ oleoyl-CoA were used as substrates, and activity was determined by formation of $\left[{ }^{14} \mathrm{C}\right] \mathrm{PA}$.

\section{Western blot analysis}

Total cell lysate $(40 \mu \mathrm{g})$ from the V5-AGPAT9-LF and vector alone were resolved on 10\% SDS-PAGE followed by transfer on to nylon membrane (Millipore, Billerica, MA, USA). The membrane blocked with $5 \%$ non fat milk containing $0 \cdot 2 \%$ Tween -20 and then incubated with V5 antibody conjugated to horse radish peroxidase (HRP; Invitrogen) for $2 \mathrm{~h}$ at room temperature, the membrane was washed and then incubated ECL reagent (GE Healthcare Piscataway, NJ, USA) to visualize the immunoreactive protein.

\section{Immunofluorescence microscopy}

Stable expressing AGPAT9-EGFP CHO cells were grown on cover slip 1 day before the experiment. Cells were fixed/permeabilized by incubation with methanol $\left(-20^{\circ} \mathrm{C}\right)$ for $20 \mathrm{~min}$. Cells were washed $3 \times 5 \mathrm{~min}$ with PBS and then incubated with primary antibody $(\sec 61 \beta$; Upstate, Lake Placid, NY, USA diluted in the ratio of 1:200) for $30 \mathrm{~min}$ at $37^{\circ} \mathrm{C}$ in a humidified chamber. Cells were then washed $3 \times 5 \mathrm{~min}$ with PBS and incubated with AlexaFluor 555 coupled fluorescent secondary antibody (Invitrogen) for $30 \mathrm{~min}$ at $37^{\circ} \mathrm{C}$ in a humidified chamber. After incubation, cells were washed $3 \times 5$ min with PBS and mounted on a glass slide with Mowiol. Cells were observed with a Zeiss Axioplan 2E, and pictures were captured with a Hamamatsu monochrome digital camera (Hamamatsu City, Japan). Images were analyzed with Openlab (Improvision, Lexington, MA, USA).

For live cell imaging, the cells were seeded in dishes and transfected with equal amount of AGPAT1-REP and AGPAT9-GEP expression plasmids. Cells were imaged directly $72 \mathrm{~h}$ after transfection using a DeltaVision RT Deconvolution Microscope (Applied Precision, LLC; Issaquah, WA, USA). The obtained images were deconvoluted to remove the reflective fluorescence using softWoRx software.

\section{Results}

\section{Cloning of the human AGPAT9}

Based on in silico sequence assembly, the human AGPAT 9 was amplified from the omental adipose tissue RNA. The amplified sequences showed that the start of the ORF for human AGPAT9 was in good context for the Kozak rule in initiating protein translation (Kozak 1984) predicting a protein of 432 residues. However, based on protein sequence homology, only a truncated form had been cloned, missing an N-terminal sequence (Fig. 1). Thus, based on human genomic sequences, we then designed additional primers to amplify the $5^{\prime}$-region sequences. The assembled sequences for AGPAT9-long form (AGPAT9-LF) had an in-frame stop codon located 60 nucleotides upstream in the $5^{\prime}$-untranslated region, suggesting that this ATG codon is most likely used as a translational start codon. The predicted protein consists of 534 residues and molecular weight of $59147 \mathrm{Da}$. Alignment of AGPAT9-LF from several species showed that this isoform was highly conserved and is also present in invertebrates like fruit fly (Drosophila melanogaster). The putative conserved motifs, $\mathrm{NHX}_{4} \mathrm{D}$ and EGTR, seen in almost all proteins of the glycerophospholipid acyltransferase family, were modified to $\mathrm{PHX}_{4} \mathrm{D}$ and EGTC respectively in both the AGPAT-SF and the AGPAT9-LF. 


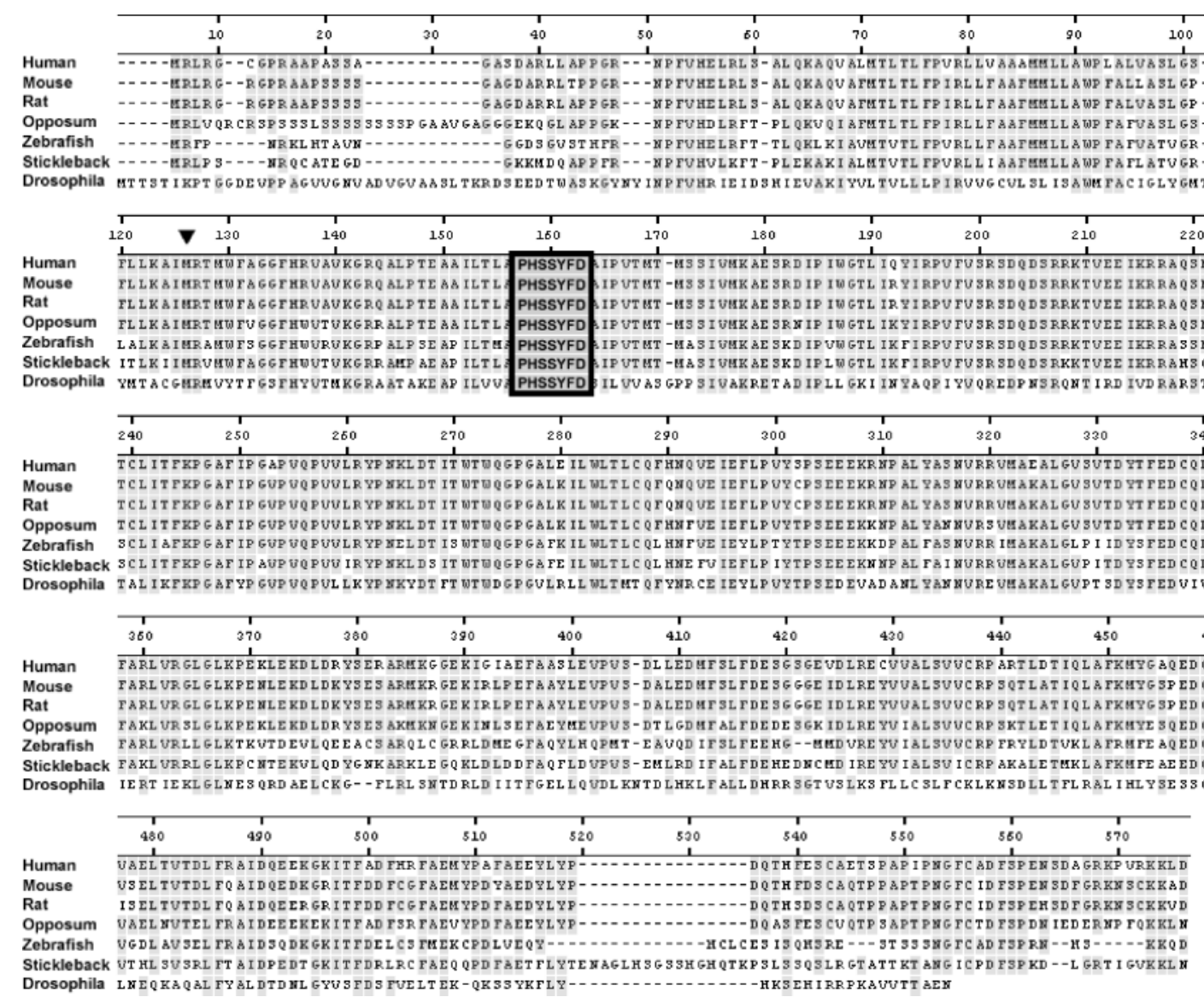

Figure 1 Alignment of protein sequences of AGPAT9 for various species. Multiple protein alignment of human, mouse, rat, opossum, zebrafish, and stickleback and fruit fly AGPAT9 amino acid sequences. The conserved motifs PHX ${ }_{4} \mathrm{D}$ and EGTC are boxed. The identical and conserved residues are shaded gray. The start of the protein sequence for the short form of AGPAT9 is shown by $\boldsymbol{\nabla}$ GeneBank accession numbers: Human AGPAT9; this study and NM_024830, NP_0791061; mouse: NM_145376, NP_663351; rat: XM_341747, XP_341748; opossum: AAFR02008846; stickleback; from trace database and zebrafish: XM_701606, XP_706698; fly: NP_001036265.

\section{Human AGPAT9 genomic organization}

A search against the human genomic databases localized the human gene on chromosome $5 \mathrm{p} 15.5$. Based on the predicted sequences and the amplified sequences, the exon-intron boundaries were determined. The gene contains 14 exons with the last exon having a long untranslated region (Table 2). All the exon and intron junctions obeyed the AG-GT dinucleotide acceptor-donor rule. Visual inspection of the sequences revealed two regions of repeat sequences located in introns 1 and 2. As shown in Fig. 2, the first repeat consisted of a sequence of 17 nucleotides and was located 130 nucleotides from exon 2 . The other repeat sequence located in intron 2 was nearly $3.5 \mathrm{~kb}$ from the splice site junction of exon 3 . This repeat sequence, although not a perfect dinucleotide repeat, can still form a stretch of the alternating purine-pyrimidine polynucleotides. It is interesting to note that the short form of AGPAT9 starts in the exon 3 and could be the result of these repeat sequences.
Tissue distribution and quantitative expression in human tissue panel

Northern blot analysis of human tissues showed that the AGPAT9 mRNA was close to $4 \cdot 4 \mathrm{~kb}$ and expressed in several tissues, with the lung and spleen expressing high levels, followed by the brain, heart, and placenta (Fig. 3). We did not observe any alternative transcript, even upon long exposure. In the rodents, a single transcript of about $4 \mathrm{~kb}$ has been identified in the lung and spleen (Chen et al. 2006). In the rat, AGPAT9 is also expressed in the stomach, but not in the mouse (Chen et al. 2006) indicating species variation. In our human northern blot, the stomach RNA was not represented. As reported earlier, the human AGPAT2 isoform is highly expressed in the liver and pancreas (Eberhardt et al. 1997) and in the adipose tissue (Agarwal et al. 2004) with relatively low expression in the lung and spleen. These RNA analyses indicate differential pattern of RNA expression of AGPAT2 and AGPAT9 isoforms in human tissues. Whether there are 
Table 2 The exon-intron boundary sequences for human AGPAT9. Intronic sequences are in lower case whereas exonic sequences are in uppercase letters. The splice site acceptor and donor dinucleotide are in bold

\begin{tabular}{|c|c|c|c|c|c|}
\hline & Length $(b p)$ & cDNA position & Acceptor & Donor & Intron \\
\hline \multicolumn{6}{|c|}{ Exon number } \\
\hline 1 & 164 & $1-264$ & & GAAGGCCCAGgtgggtgccag & 1 \\
\hline 2 & 143 & $265-407$ & ctctgtctgcagGTGGCCСТCAT & TGTGGAGGAAgtaagttgcgcg & 2 \\
\hline 3 & 215 & $408-622$ & ccctcttttgcagGGTTGTGGACTT & ATCTGGGGAAgtgagtgagaca & 3 \\
\hline 4 & 113 & $623-735$ & cctctcttccagCTCTGATCCAGT & GTGGCCACAGgtaatgcacgta & 4 \\
\hline 5 & 61 & $736-796$ & ccacttccagATAATGATTTT & TTCAAACCTGgtatgtagtttt & 5 \\
\hline 6 & 59 & $797-855$ & cctttctcggagGTGCATTCAT & AAATAAACTGgtgagttgtgt & 6 \\
\hline 7 & 35 & $856-890$ & cttcctcCCcagGACACCATCACA & GACCTGGAGC gtaagttgaacg & 7 \\
\hline 8 & 55 & $891-945$ & tctgtttttaagGCTGGAAATCCT & GGAAATCGAGgttcgtatggat & 8 \\
\hline 9 & 83 & 946-1028 & tctgtgtgctcagTТССТТССТGТG & TCATGGCCGAgtaagtgagcagc & 9 \\
\hline 10 & 126 & $1029-1154$ & gccctccttgtagGGCCTTGGGT & GGGGCCTCGGgtgagtacctggt & 10 \\
\hline 11 & 154 & 1155-1308 & ttttttgtctagGCTAAAACCA & GTTCGACGAGgtagggcctgtcg & 11 \\
\hline 12 & 99 & 1309-1407 & tctctccccacagAGCGGCAGCG & GGCTTTCAAGgtgagtgcagagtt & 12 \\
\hline 13 & 142 & $1408-1549$ & tttgccttgcagATGTACGGAGC & ATCACATTCGgtgagcccgcagg & 13 \\
\hline 14 & 185 & 1550 & tttgtctttccagCTGACTTCCACA & & \\
\hline
\end{tabular}

functional redundancies among these isoforms remains unclear.

We expanded our search for expression in the human tissues by using quantitative real-time PCR. Shown in Table 3 are the $\Delta C_{\mathrm{t}}$ values for various tissues after normalization to the housekeeping gene, glycerol-3-phosphate dehydrogenase (G3PDH). Quantitative real-time PCR revealed that AGPAT9 had about twofold higher expression in the lung

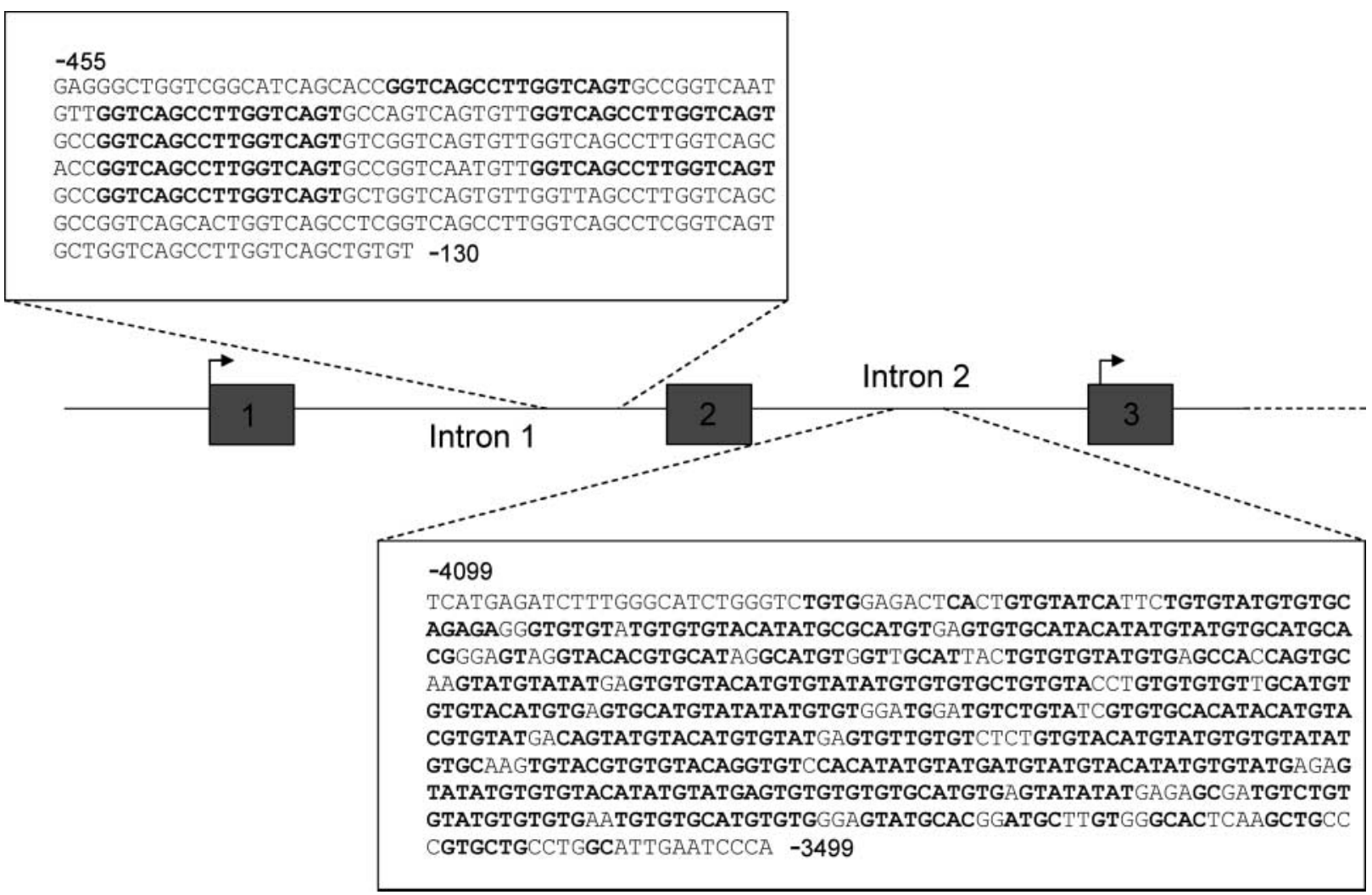

Figure 2 Nucleotide repeat sequences located in the intron of AGPAT9 gene: Shown is the partial gene structure for AGPAT9 gene where filled boxes represent exons, not drawn to scale. The 17 nucleotide repeat sequence, GGTCAGCCTTGGTCAGT, located in intron 1 are shown in bold which are located 130 nucleotides upstream from exon 2. The alternating pyrimidine (cytosine and thymine) and purine (guanine and adenine) sequences in intron 2 are located 3499 nucleotide upstream of exon 3 and are shown in bold. The two putative transcriptional start sites are marked with arrows. 
A

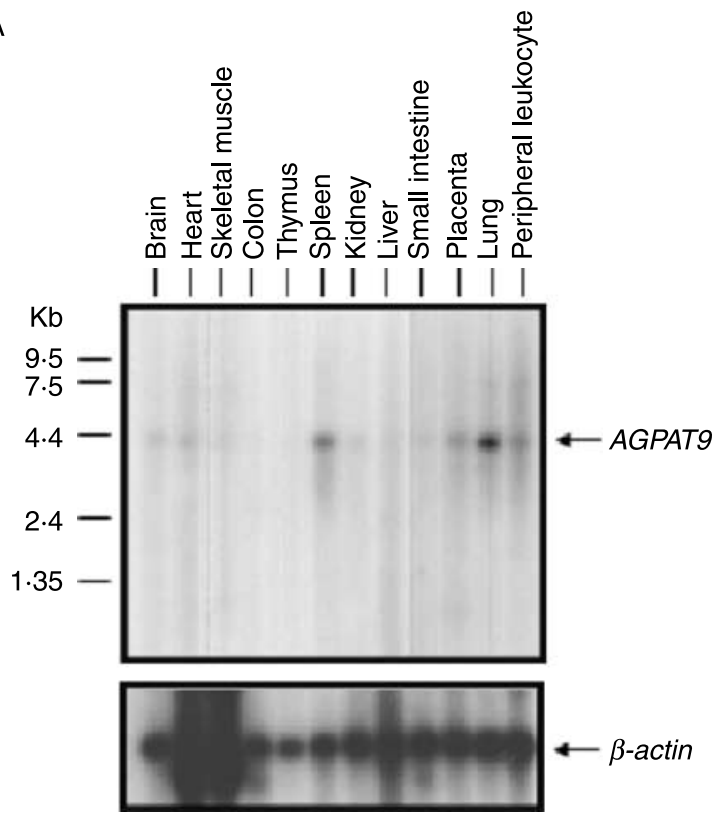

B

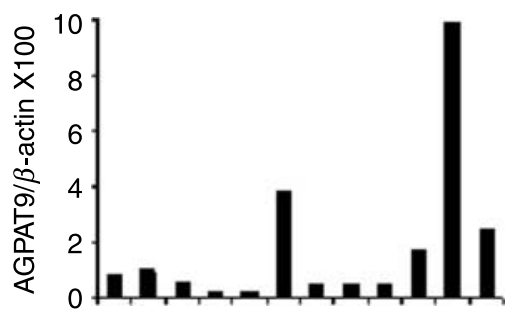

Figure 3 Northern blot analysis. (A) Human multiple tissue blot containing $10 \mu \mathrm{g}$ poly $(\mathrm{A})^{+}$RNA for each tissue was hybridized with ${ }^{32} \mathrm{P}$-CDNA for human AGPAT9 sequences. The blot was hybridized and washed as described in methods. The blot was exposed for 4 days at $-80^{\circ} \mathrm{C}$ to detect any weak signal. The blot was stripped and reprobed with $\beta$-actin cDNA as an internal control and exposed for $16 \mathrm{~h}$. (B) Shown are the ratio for the AGPAT9 and $\beta$-actin expressed as an arbitrary units.

than in the spleen. AGPAT9 was also expressed in the omental adipose tissue and placenta, but about sevenfold less than the lung. AGPAT9 is expressed poorly in the skeletal muscle.

\section{Comparison of amino acid sequence with other known} acyltransferases

Multiple sequence alignment of the known human acyltransferases revealed that AGPAT9 belongs to the family of acyltransferases (Fig. 4A). Previous studies have revealed that AGPATs $1-5$ and 8 have the same two conserved motifs, $\mathrm{NHX}_{4} \mathrm{D}$ and EGTR, as shown in Fig. 4B. As more of these acyltransferases are cloned and sequenced there appears to be flexibility in these conserved motifs. The conserved proline in AGPAT9 from several species indicates that the asparagine residue in the $\mathrm{NHX}_{4} \mathrm{D}$ motif is not an absolute requirement
Table 3 Tissue distribution of human AGPAT9 as quantified by TaqMan real-time PCR. Shown are the mean $\Delta C_{\mathrm{t}}$ values, performed in duplicate and corrected for internal control, G3PDH. Fold increase between isoforms in various tissues were calculated 2$\Delta C_{\mathrm{t}}$ according to $\mathrm{ABI}$ bulletin $\# 2$. Expression in the lung and spleen are about the same, but about $3 \cdot 27$-fold less in the leukocyte when compared with the lung. Placenta and adipose tissues express at similar levels but are about 6.96-fold less than the lung. Our TaqMan probe does not distinguish between the AGPAT9-LF and the AGPAT9-SF

\begin{tabular}{|c|c|c|c|}
\hline & $C_{\mathrm{t}}$ values & Tissue & $C_{\mathrm{t}}$ values \\
\hline \multicolumn{4}{|l|}{ Tissue } \\
\hline Heart & $10 \cdot 01$ & Prostate & $8 \cdot 00$ \\
\hline Brain & $7 \cdot 53$ & Testis & $7 \cdot 99$ \\
\hline Placenta & $6 \cdot 14$ & Ovary & $7 \cdot 86$ \\
\hline S. muscle & $13 \cdot 41$ & S. intestine & $8 \cdot 23$ \\
\hline Kidney & $8 \cdot 39$ & Colon & $8 \cdot 41$ \\
\hline Pancreas & $6 \cdot 87$ & Leukocyte & $4 \cdot 91$ \\
\hline Lung & $3 \cdot 20$ & Adipose & $6 \cdot 00$ \\
\hline Spleen & 3.95 & Liver & $8 \cdot 54$ \\
\hline Thymus & $7 \cdot 37$ & & \\
\hline
\end{tabular}

for the enzymatic activity. Likewise, substitution of arginine to cysteine in EGTR motif is also tolerated (Fig. 1). In Synechocystis sp. PCC6803, an unrelated acyltransferase had the EGAT sequence instead of the motif EGTR (Weier $e t$ al. 2005). In a recent study, using in vitro translated mouse acyltransferases, it was shown that Agpat 3, 4, and 5 possessed acyltransferase activity, which was only $41-48 \%$ of mouse Agpat2 (Lu et al. 2005).

\section{Subcellular localization of AGPAT9-LF-GFP}

In stably expressing $\mathrm{CHO}$ cells, the AGPAT9-LF-GEP protein showed an endoplasmic reticulum (ER) like expression pattern. This was confirmed by colocalizing AGPAT9-LF-GFP with the ER protein Sec $61 \beta$ (Fig. 5A). AGPAT9-LF-GFP also colocalized with the ER proteins disulfide isomerase and the ER-chaperone GRP78/BIP (data not shown). Since previous studies have shown that AGPAT1, 2, 6, and 8 are all localized to the ER, we tried to determine whether, the AGPAT9-LF is localized to the same or different subdomain of ER. We transiently transfected CHO cells with AGPAT9-LF-GFP and AGPAT1-REP and captured images for both the proteins using live cells imaging. Shown in Fig. 5B are the fluorescence for AGPAT9-LF and AGPAT1 indicating that the two proteins appear to colocalize to similar ER domains. However, further colocalization studies with higher resolution will further confirm this observation.

\section{AGPAT activity}

The human AGPAT9-SF has moderate acyltransferase activity, only $22 \cdot 6 \%$ when compared with the other isoform, human AGPAT2, using oleoyl-CoA as the acyl donor and 1-oleoyl glycerol-3-phosphate as the acceptor (data not 
A

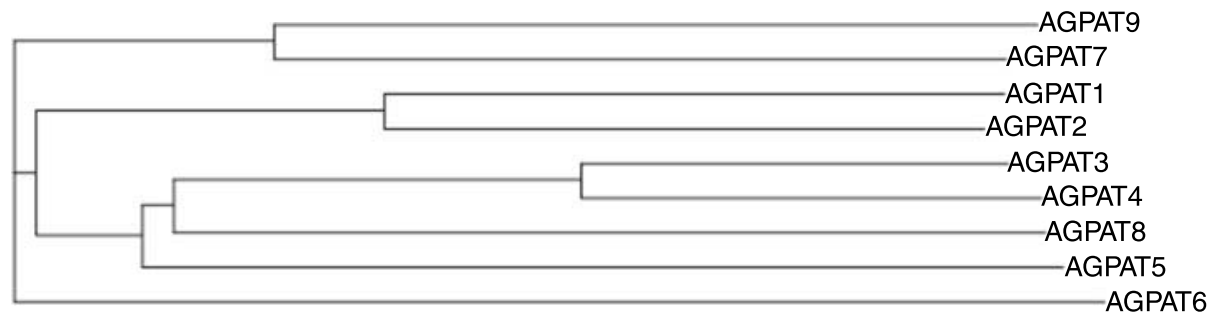

B AGPAT2 93 VIVSNHQSILDMMGL 107....168 WIYPEGTRNDNG 179

AGPAT 491 IVVLNHKEEIDELCG $105 \ldots . .173$ LIHCEGTRFTEK 184

AGPAT 6243 ICVANHTSPIDVIIL 257....318 LIF PEGTCINNT 329

AGPAT 80 VIIMNHRTRMDWMFL $94 \ldots . . . .162$ LIF PEGTDLTEN 173

AGPAT 9130 LTLAPHSSYEDAI PV 144....204 MIFPEGTCTNRT 215

Figure 4 Evolutionary dendrogram and conserved protein motifs among AGPATs. (A) The dendrogram was computed from the aligned protein sequences using the ClustralW algorithm and VectorNTi's phylogenetic tree program with default settings. (B) Alignment of the partial amino acid sequences of AGPAT isoforms 2, 4, 6, 8, and 9 showing the conserved $(\mathrm{N} / \mathrm{P}) \mathrm{HX}_{4} \mathrm{D}$ and $\mathrm{EGT}(\mathrm{R} / \mathrm{D} / \mathrm{C})$ motifs. Conserved residues are shown in bold.

shown). We then created a V5- epitope tagged AGPAT9-LF and determined the acyltransferase activity as above. This long form has much higher activity $(72 \cdot 8 \%$ when compared with AGPAT2) than the AGPAT9-SF, indicating that the amino terminus residues increase its activity over threefold (Fig. 6A and $\mathrm{B})$.

\section{Substrate specificity of AGPAT9-LF in CHO cell lysates}

To assess the substrate specificity of AGPAT9-LF, LPAs with various fatty acids at the $s n-1$ position were incubated with lysates of CHO cells over expressing wild-type AGPAT9 and $\left[{ }^{14} \mathrm{C}\right]$ oleoyl-CoA. Wild-type AGPAT9 accommodated myristoyl, linoleoyl, and palmitoyl fatty acids at the $s n-1$ position of the LPA, synthesizing PAs at about the same rate as the preferred substrate, $s n$-1-oleoyl-LPA (Table 4). Other LPAs, such as $s n-1$-linolenoyl, and $s n$-1-arachidonoyl were esterified at $50-70 \%$ the rate of $s n-1$-oleoyl-LPA. However, $s n-1$-arachidoyl form of LPA was not esterified.

To assess the specificity of AGPAT9-LF for the other substrate, the fatty acyl-CoA esterified to the $s n-2$ position, cell lysates were incubated with $\left[{ }^{3} \mathrm{H}\right] \mathrm{LPA}$ with various unlabeled acyl-CoAs. Wild-type AGPAT9 used palmitoylCoA, myristoyl-CoA, and stearoyl-CoA at the rate of about $25 \%$ of the preferred substrate oleoyl-CoA, (Fig. 8B). All other acyl-CoAs were poor substrates when compared with oleoyl-CoA (Table 5).

\section{LPCAT1 activity in stable cell lines and mouse tissue} homogenates

While this study was in progress, two independent studies showed that the mouse homolog has acyl-CoA:LPCAT1 activity and that the enzyme is highly expressed in the lung (Chen et al. 2006, Nakanishi et al. 2006). Although, the mouse clone is $88 \%$ identical to our human AGPAT9, in our hands stable CHO lines expressing AGPAT9 lacked LPCAT activity, whether determined using whole cell lysate (Fig. 7A) or in cell fractions (data not shown). Such LPCAT activity, even though small, could be observed in the mouse lung and spleen tissue homogenates (Fig. 7B).

\section{Discussion}

We have cloned the cDNA for a human acyltransferase, AGPAT9, which has much higher expression in the lung and spleen, followed by the placenta, and leukocytes. In omental adipose tissue, the expression of AGPAT9 is moderate. In cell lysates obtained from cultured cells over-expressing AGPAT9, both the short and the long forms of AGPAT9 catalyze the synthesis of PA. However, the enzymatic activity of SF was markedly lower when compared with that of AGPAT2, whereas the LF was only slightly lower than that of AGPAT2. Thus, AGPAT9 resembles other AGPAT isoforms, such as AGPAT3, 4, 5, and 8 which also have lower activity than AGPAT2 (Lu et al. 2005). As this study was in progress, a cDNA for a mouse acyl-CoA:LPCAT1 was reported with the similar sequence as our human AGPAT9 cDNA (Chen et al. 2006, Nakanishi et al. 2006). This same sequence has also been reported as phosphonoformate immuno-associated protein 3 (PFAAP3; UniProtKB/Swiss-Prot entry Q8NF37). However, we did not observe any LPCAT activity in whole cell lysate obtained from $\mathrm{CHO}$ cells overexpressing AGPAT9. The reasons why the two identical sequences (mouse and human clones are $88 \%$ identical) show a different spectrum of enzymatic activities than previously reported are not known. One possibility could be the different host cells used for the protein expression. While we employed $\mathrm{CHO}$ cells, other investigators used COS-7 (monkey kidney cell) and HEK-293 (human embryonic kidney cells; Chen et al. 2006). Differences in enzymatic activity might result from 
A

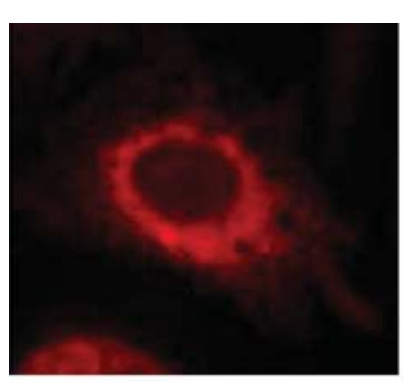

B

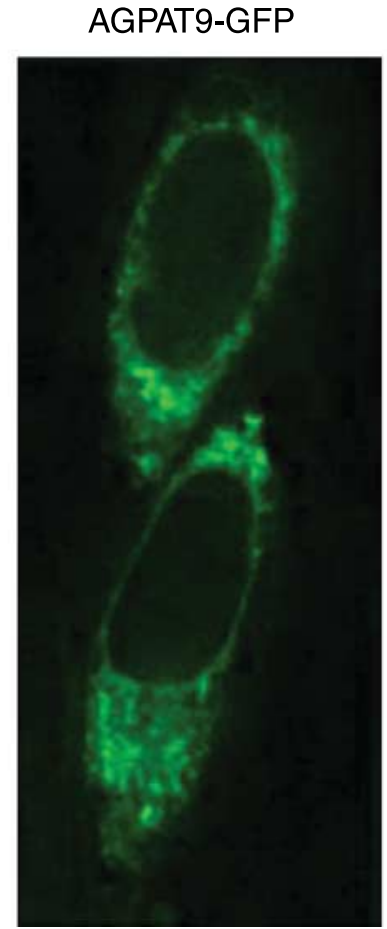

GFP

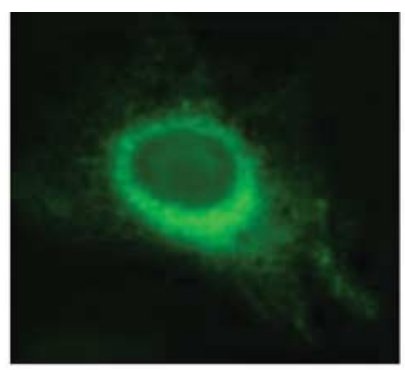

AGPAT1-RED

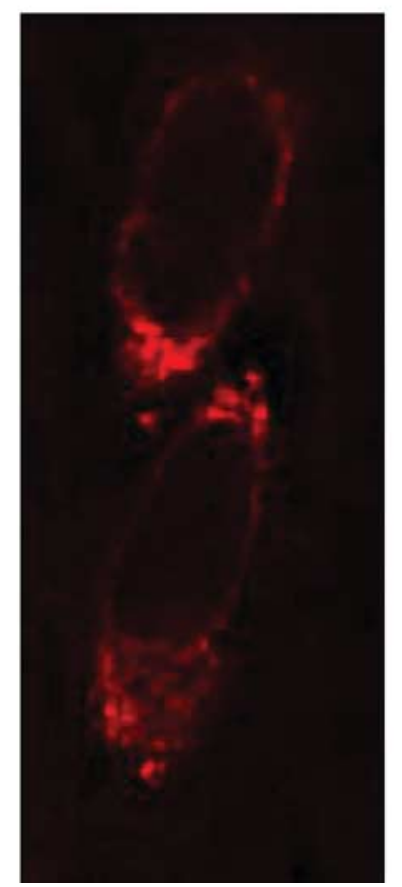

Overlay

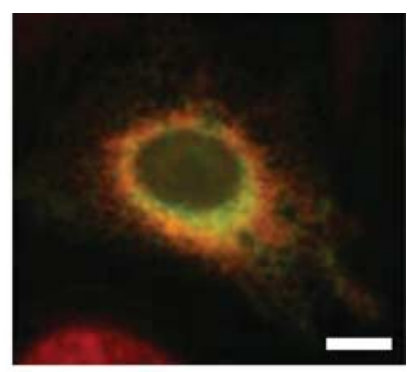

Overlay

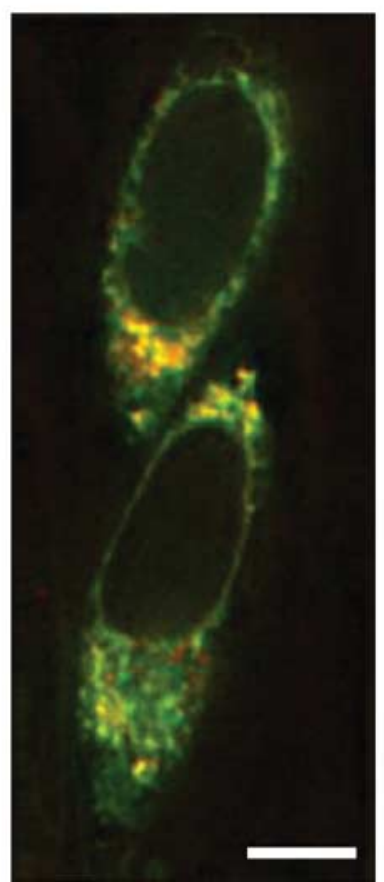

Figure 5 Colocalization of AGPAT9-GFP to endoplasmic reticulum and AGPAT1-RFP in stably or transiently expressing CHO cells: (A) Overexpressing AGPAT9-GFP (long form) $\mathrm{CHO}$ cell were fixed in methanol and incubated with antibody, Sec $61 \beta$, specific for endoplasmic reticulum and imaged for green and red fluorescence using fluorescence microscope. Shown is a representative cell for section 61 (red fluorescence), AGPAT9 (green fluorescence) and the merge. (B) For live cell imaging, cells were grown in culture dishes and transfected with equal quantities of both the constructs, AGPAT9-LF-GFP, and AGPAT1-REP. Fluorescence images were acquired $72 \mathrm{~h}$ after transfection using fluorescence microscope equipped with incubation camber with temperature and $\mathrm{CO}_{2}$ controls. Shown is a representative cell for AGPAT9 (green fluorescence), AGPAT1 (red fluorescence) and the merge. Scale bar $=10 \mu \mathrm{m}$.

improper post-translational processing of the recombinant protein. A robust expression system needs to be established to resolve this issue.

The AGPAT9 protein is highly conserved among species, and homologs are found in rodents, vertebrate fishes and invertebrate fruit fly (GenBank entry as a hypothetical protein). Our search did not show this protein to be present in plants, but this may be due to incomplete genome annotation in many of these species. The high degree of homology (Fig. 1) and conservation among species suggests that the AGPAT9 gene evolved very early during evolution suggesting that this enzyme serves an important function in cellular physiology in tissues other than the lung as indicated by previous investigators (Chen et al. 2006, Nakanishi et al. 2006). However, unlike mouse LPCAT1 (Chen et al. 2006, Nakanishi et al. 2006), AGPAT9 does not appear to use LPC as substrate in our in vitro studies, which would argue against its sole role in lung physiology. Our data show that the 
A

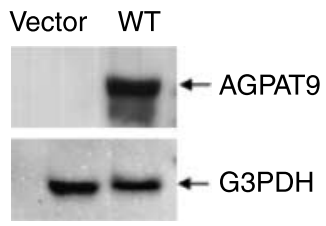

B

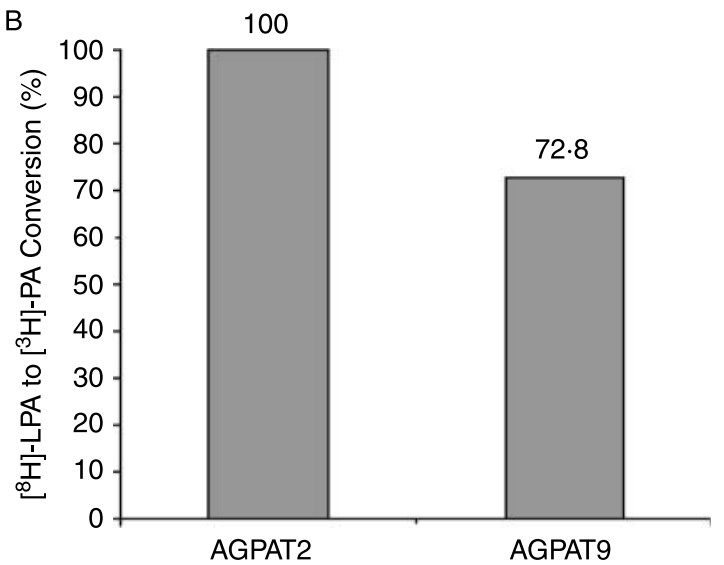

Figure 6 The enzymatic activities of wild-type human AGPAT2, and long forms of AGPAT9 in stably expressing $\mathrm{CHO}$ cells. (A) Shown is the Western blot for the cell pool, used for determining the acyltransferase activity, for the V5-epitope tagged AGPAT9-long form as probed with $\mathrm{V} 5$-antibody. G3PDH is included to demonstrate equal loading. (B) The enzymatic activities were determined as percentage conversion of ${ }^{3} \mathrm{H}$-LPA to ${ }^{3} \mathrm{H}-\mathrm{PA}$ in the presence of oleoyl-CoA. The LPA to PA conversion in control cells was subtracted from the values as described before (9). Shown are the mean values from 3-4 independent cell pools assayed in triplicate. Values are computed against the wild-type AGPAT2 activity as $100 \%$.

enzyme is present in the spleen as well, suggesting its role in the immune system. Secondly, fruit flies lack tissue equivalent to the lung. Finally, presence of the LPCAT activity in the lung and spleen tissues represents the total LPCAT activity,

Table 4 Specificity of human wild type recombinant AGPAT9 long form for $s n$-1-lysophosphatidic acid acceptor. The enzymatic activities were determined using oleoyl-CoA as donor and various medium and long chain fatty acids at $s n-1$ position of lysophosphatidic acid as an acceptor. All enzymatic activities were determined in two independent experiments in triplicate. The enzymatic activities are compared with $s n$-1-oleoyl-lysophosphatidic acid

Carbon chain: number of double bonds

$\%$ Activity

Fatty acid at position of sn-1-LPA

$\begin{array}{lll}\text { Oleoyl } & \text { C18:1 } & 100 \\ \text { Myristoyl } & \text { C14:0 } & 84 \\ \text { Palmitoyl } & \text { C16:0 } & 86 \\ \text { Linoleoyl } & \text { C18:2 } & 78 \\ \text { Linolenoyl } & \text { C18:3 } & 68 \\ \text { Arachidoyl } & \text { C20:0 } & 34 \\ \text { Arachidonoyl } & \text { C20:4 } & 36\end{array}$

Table 5 Specificity of human wild type recombinant AGPAT9 long form for acyl-CoA donor. The enzymatic activities were determined using sn-1-oleoyl-lysophaphatidic acid as an acceptor and various medium and long chain fatty acids as donor. All enzymatic activities were determined in two independent experiments in triplicate. The enzymatic activities are compared with oleoyl-CoA which is computed as $100 \%$. Where: $n-3, n-6, n-9$ indicate the position of the first double bond from the $\mathrm{CH}_{3}$ end of the molecule

\begin{tabular}{llr} 
& $\begin{array}{l}\text { Length of carbon chain: } \\
\text { number of double bonds }\end{array}$ & $\%$ Activity \\
\cline { 2 - 2 } Acyl-CoA & & \\
Oleoyl & $\mathrm{C} 18: 1$ & $100 \cdot 0$ \\
Decanoyl & $\mathrm{C} 10: 0$ & $9 \cdot 5$ \\
Lauroyl & $\mathrm{C} 12: 0$ & $9 \cdot 8$ \\
Myristoyl & $\mathrm{C} 14: 0$ & $26 \cdot 7$ \\
Palmitoyl & $\mathrm{C} 16: 0$ & $29 \cdot 3$ \\
Stearoyl & $\mathrm{C} 18: 0$ & $16 \cdot 8$ \\
Linolenoyl & $\mathrm{C} 18: 3, n-3$ & $7 \cdot 0$ \\
$\gamma$-linolenoyl & $\mathrm{C} 18: 3, n-6$ & $5 \cdot 6$ \\
Arachidoyl & $\mathrm{C} 20: 0$ & $11 \cdot 4$ \\
Arachidonoyl & $\mathrm{C} 20: 4, n-6$ & $6 \cdot 2$ \\
Behenoyl & $\mathrm{C} 22: 0$ & $9 \cdot 1$ \\
Decosahexaenoyl & $\mathrm{C} 22: 6, n-3$ & $11 \cdot 7$ \\
Tricosanoyl & $\mathrm{C} 23: 0$ & $12 \cdot 9$ \\
Lignoceroyl & $\mathrm{C} 24: 0$ & $7 \cdot 2$ \\
Nervonoyl & $\mathrm{C} 24: 1, n-9$ & $9 \cdot 1$ \\
Hexaconosanoyl & $\mathrm{C} 26: 0$ & $7 \cdot 9$ \\
& &
\end{tabular}

which may or may not be due to the LPCAT1 activity. Lack of LPCAT activity in the recombinant protein will require further studies with more robust expression system.

The gene structure has revealed some interesting features. The presence of intergenic 17 nucleotide repeat sequence in intron 1 and alternating purine pyrimidine (APP) sequences in the intron 2 could influence the alternate splicing with shorter transcript originating in exon 3 of the AGPAT9 gene (Hui et al. 2005). However, not directly demonstrated, these nucleotide repeat sequences, have been shown to influence the expression of a number of genes including $11 \beta$-hydroxysteroid dehydrogenase 2 (Agarwal 2001). The fact that the short form of the AGPAT9 is also enzymatically active and the APP regulates the
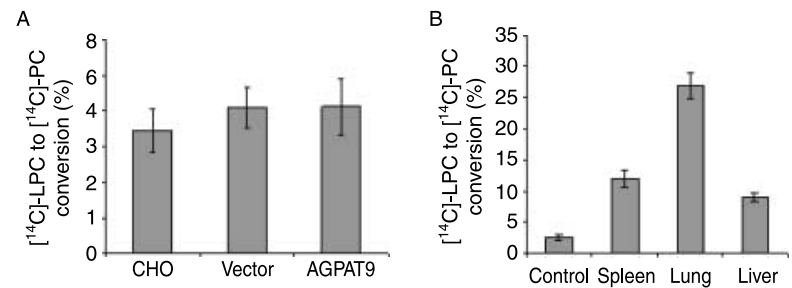

Figure 7 Lysophosphatidylcholine acyltransferase enzymatic activity of AGPAT9-LF in the stably expressing cell lysate and mouse tissue homogenate: (A) Shown is the LPCAT activity for the $\mathrm{CHO}$ cells, vector alone, and AGPAT9-long form in $\mathrm{CHO}$ cells determined by conversation of $\left[{ }^{14} \mathrm{C}\right] \mathrm{LPC}$ to $\left[{ }^{14} \mathrm{C}\right] \mathrm{PC}$. Values are mean of 2-3 independent experiments in triplicate. (B) LPCAT enzymatic activity in the mouse spleen, lung, and liver is included as a control where tissue homogenate was omitted. Values are from two independent experiments in triplicate. 
expression of several genes, might suggest why we initially cloned the short form for AGPAT9. The study of the enzymatic activities of the long and short forms of AGPAT9 also reveal that the first 102 residues at the amino terminus of the protein increase the enzymatic activity, suggesting a physiological role of alternative splicing in this gene.

This study corroborates the previous study that AGPAT9 localizes to the ER using different set of ER-resident proteins, Sec $61 \beta$. This study also shows that AGPAT1, another ER-resident acyltransferase, and AGPAT9 partially colocalize, i.e. they are present in the similar ER domain.

The two signature motifs are highly conserved among the acyltransferase superfamily, $\mathrm{NHX}_{4} \mathrm{D}$, and EGTR (Agarwal \& Garg 2003, Leung 2001), but these motifs have amino acid substitutions in AGPAT9. The $\mathrm{NHX}_{4} \mathrm{D}$ motif has asparagine substituted with proline while in the EGTR motif arginine is replaced with cysteine, EGTC. Thus, asparagine in $\mathrm{NHX}_{4} \mathrm{D}$ and arginine in EGTR may be conserved amongst acyltransferases, but are not required for absolute enzymatic activity, at least in AGPAT9 (this study) and in AGPAT8, as reported previously (Agarwal et al. 2006). Thus, the conserved $\mathrm{NHX}_{4} \mathrm{D}$ motif can now be represented as $(\mathrm{N} / \mathrm{P})$ $\mathrm{HX}_{4} \mathrm{D}$ where asparagine is not critical for the enzymatic activity.

We have previously reported the role of hydrophobic residues downstream to the $\mathrm{NHX}_{4} \mathrm{D}$ motif to be important for the enzymatic activity (Agarwal et al. 2006). Similar, strongly hydrophobic region is obvious in the AGPAT9 as well (Fig. 8); suggesting that these hydrophobic residues might similarly fold to form a hydrophobic tunnel to accommodate the acyl chain, as observed with the tertiary structure of squash (Cucurbita moschata) chloroplast gpat (Turnbull et al. 2001a,b, Slabas et al. 2002, Tamada et al. 2004). Analysis of the predicted secondary structure of gpat and AGPATs show that the positioning of the $\mathrm{HX}_{4} \mathrm{D}$ domain is in the loop region between a beta strand $\left(\beta_{c}\right)$ and alpha helix

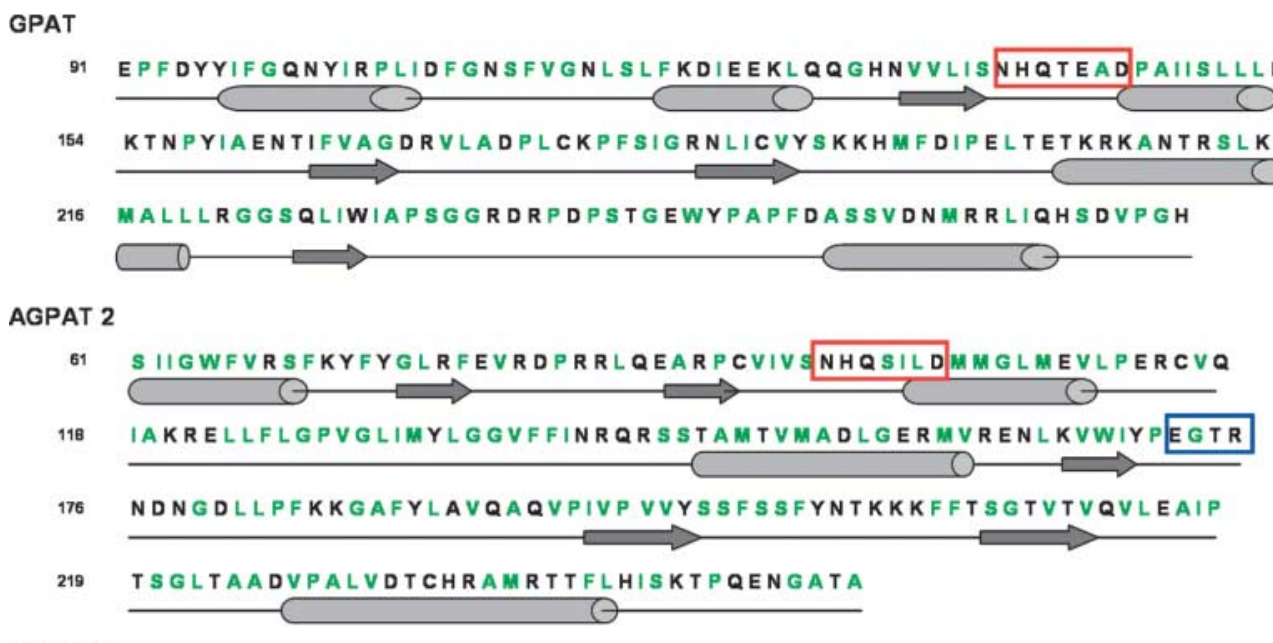

AGPAT 9

61 AAAMMLLAWPLALVASLGSAEKEPEQPPALWRKVVDFLLKAIMRTMWFAGGFHRVAV 118 KGRQALPTEAAILTLAPHSSYFDAIPVTMTMSSIVMKAESRDIPIWGTLIQYIRPVFVS

177 RSDQDSRRKTVEEIKRRAQSNGKWPQIMIFPEGTRNRTCLITFKPGAFIPGAPVQPVV 236 LRYPNKLDTITWTWQGPGALILWLTLCQFHNQVE

Figure 8 Partial protein sequence of human AGPAT2 and AGPAT9, and squash (Cucurbita moschata) chloroplast gpat showing the predicted secondary structure: Based on gpat crystal structure, the region between residues 91 and 270 was selected, which includes the enzyme's active site, $\mathrm{NHX}_{4} \mathrm{D}$. Based on sequence homology between various isoforms of AGPAT1 through AGPAT9 (data not shown), protein region between amino acids, 61 and 270, were selected for secondary structure prediction of AGPAT2 and AGPAT9. Secondary structure prediction was carried out using Predict protein server (www.predictprotein.org; PredictProtein: Rost et al. 2004) W321-W326). Shown are the partial protein sequences flanking the conserved $(\mathrm{N} / \mathrm{P}) \mathrm{HX}_{4} \mathrm{D}$ motif boxed in red and $\mathrm{EGT}(\mathrm{R} / \mathrm{C})$ motif in blue. All hydrophobic residues are shown in green, including the weakly hydrophobic residues glycine, $(\mathrm{G})$, and serine, (S). Below each protein sequence is shown the predicted secondary structure. $\alpha$-Helix (shaded barrel), $\beta$-sheet (shaded arrow), and unstructured or random coil as a straight line. In all the three protein sequences, the $(\mathrm{N} / \mathrm{P}) \mathrm{HX}_{4} \mathrm{D}$ is flanked by beta-sheet and alpha helix and predicted to fold as determined for gpat creating the active site of the enzymes. 
$\left(\alpha_{6}\right)$. The positioning of the other secondary structure elements also fall in a similar way for AGPAT2 and AGPAT9, which is comparable to that of the gpat. It is important to note that even though AGPATs share 12-15\% sequence homology with gpat, these proteins are similar in the secondary structure prediction and hydrophobicity distribution, which would be the key features in determining the fold of the protein and also the active site hydrophobic tunnel. This indicates that the entire hydrophobic region is critical for the enzymatic activity and not the $\operatorname{EGT}(\mathrm{R} / \mathrm{D} / \mathrm{C})$ motif as observed in acyltransferases cloned till now. As shown in Fig. 8, the secondary structure prediction also indicates that the active site of the proteins, AGPAT2 and AGPAT9, should fold similar to the gpat as determined by X-ray crystal structure (Turnbull et al. 2001a,b, Slabas et al. 2002, Tamada et al. 2004). This would strongly suggest that the cloned enzyme should have $s n-2$ acyltransferase activity similar to AGPAT2 whose activity is now established (Fig. 9).

The physiological function of AGPAT2 has emerged from the mutational analysis of patients with CGL in humans (Agarwal et al. 2002). The loss of adipose tissue might result, from defects either in adipocyte development or in triglyceride biosynthesis. Inactivation of another isoform, Agpat6, in mice displays resistance to diet-induced obesity and subdermal loss of adipose tissue. Furthermore, the Agpat $^{-/-}$mice fail to lactate suggesting a role of AGPAT6 in diacylglycerol and triacylglycerol synthesis in mammary epithelium (Beigneux et al. 2006, Vergnes et al.
2006). Interestingly, Agpat6 mRNA is expressed at highest levels in interscapular brown adipose tissue, visceral, and subcutaneous adipose tissue as well as in mammary epithelium of breast tissue (Beigneux et al. 2006, Vergnes et al. 2006). AGPAT9, however, has a distinct pattern of expression, being highly expressed in the lung and spleen instead of in adipose tissue. Thus, it can be speculated that the deficiency of AGPAT9 might affect lung physiology and may affect immunological response (due to high expression in the spleen) instead of affecting adipocyte differentiation and development.

It is interesting to observe that so many AGPATs are now cloned. Isoforms $1-5,8$, and 9 all appear to have varying degree of acyltransferase activity. Most, isoforms 1, 2, and 6-9 are all localized to ER. This raises an important question: why would cells express all of these AGPATs localized to the ER? Are the activities redundant? Answers to these questions will emerge when detailed investigation of these AGPATs are carried out, in terms of hormonal and nutritional regulation, both at the transcriptional and translational level, tissue expression, substrate specificities and subcellular localization. To understand the physiological function of each of these AGPATs either by knocking down the activities in cultured cells or by developing the knockout mouse model shall reveal the function for each of these in specific cell types or in an integrated animal system. It is quite likely that each of these AGPATs perform a unique function within the cells, which maintain cellular membrane structure and/or produce
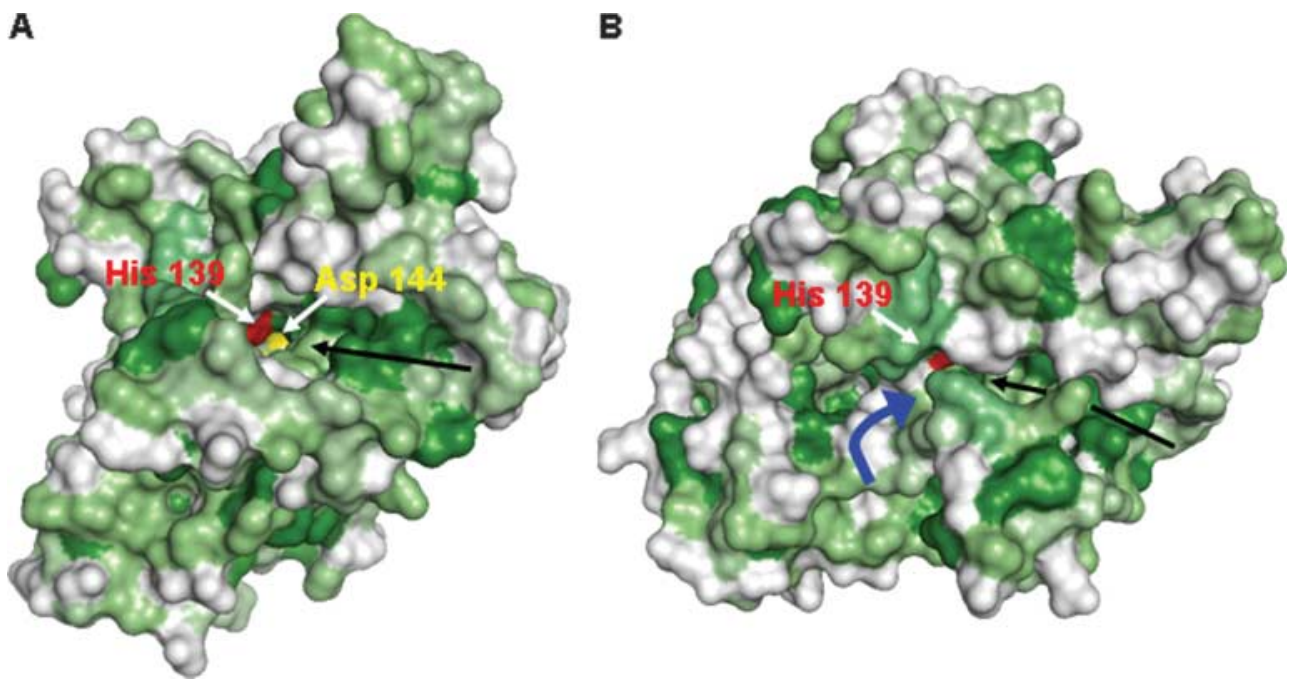

Figure 9 Space filling model for the partial squash (Cucurbita moschata) gpat protein as shown in Fig. 8. (A) The active site residues, histidine 139 in red and aspartate 144 in yellow are buried deep at the end of the hydrophobic tunnel which accommodates the acyl-CoA shown as a black arrow. The hydrophobic residues are shown in green where the green color gradient indicates the hydrophobic residues from strong (in dark green) to weakly hydrophobic residues shown in light green. (B) The same model shown at a different angle such that only the histidine (red) is visible. In this view, the glycerol-3-phosphate-binding site is exposed shown as a blue curved arrow. A straight black arrow represents the fatty acid positioned in the hydrophobic tunnel. The space filling model was created using PYMOL (DeLano Scientific LLC, San Francisco, USA). The hydrophobic scale is as follows dark green: Leu, Ile, Met, Phe, Trp; medium green: Val, Pro, Lys and light green: Ala, Tyr, His, Thr, Arg. 
specific phospholipids signaling molecule. Identification and characterization of AGPAT9 is a step towards understanding the role of these acyltransferases in human physiology.

\section{Acknowledgements}

We thank Ruth Giselle Huet, Keliang Xu, and Katie Tunison for technical assistance, Richard Auchus, MD PhD for critical review of the manuscript. This work was supported by the National Institutes of Health grant R01-DK54387 and by the Southwestern Medical Foundation. The authors declare that there is no conflict of interest that would prejudice the impartiality of this scientific work.

\section{References}

Agarwal AK 2001 Transcriptional influence of two poly purine-pyrimidine tracts located in the HSD11B2 (11beta-hydroxysteroid dehydrogenase type 2) gene. Endocrine Research 27 1-9.

Agarwal AK \& Garg A 2003 Congenital generalized lipodystrophy: significance of triglyceride biosynthetic pathways. Trends in Endocrinology and Metabolism 14 214-221.

Agarwal AK, Arioglu E, de Almeida S, Akkoc N, Taylor SI, Bowcock AM, Barnes RI \& Garg A 2002 AGPAT2 is mutated in congenital generalized lipodystrophy linked to chromosome 9q34. Nature Genetics 31 21-23.

Agarwal AK, Barnes RI \& Garg A 2004 Genetic basis of congenital generalized lipodystrophy. International Journal of Obesity and Related Metabolic Disorders 28 336-339.

Agarwal AK, Barnes RI \& Garg A 2006 Functional characterization of human 1-acylglycerol-3-phosphate acyltransferase isoform 8: cloning, tissue distribution, gene structure and enzymatic activity. Archives of Biochemistry and Biophysics 449 64-76.

Beigneux AP, Vergnes L, Qiao X, Quatela S, Davis R, Watkins SM, Coleman RA, Walzem RL, Philips M, Reue K et al. 2006 Agpat6-a novel lipid biosynthetic gene required for triacylglycerol production in mammary epithelium. Journal of Lipid Research 47 734-744.

Chen X, Hyatt BA, Mucenski ML, Mason RJ \& Shannon JM 2006 Identification and characterization of a lysophosphatidylcholine acyltransferase in alveolar type II cells. PNAS 103 11724-11729.

Coleman RA \& Lee DP 2004 Enzymes of triacylglycerol synthesis and their regulation. Progress in Lipid Research 43 134-176.

Eberhardt C, Gray PW \& Tjoelker LW 1997 Human lysophosphatidic acid acyltransferase. cDNA cloning, expression, and localization to chromosome 9q34.3. Journal of Biological Chemistry 272 20299-20305.

Garg A 2004 Acquired and genetic lipodystrophies. New England Journal of Medicine 350 1220-1234.

Haque W, Garg A \& Agarwal AK 2005 Enzymatic activity of naturally occurring 1-acylglycerol-3-phosphate-O-acyltransferase 2 mutants associated with congenital generalized lipodystrophy. Biochemical and Biophysical Research Communications 327 446-453.

Hui J, Hung LH, Heiner M, Schreiner S, Neumuller N, Reither G, Haas SA \& Bindereif A 2005 Intronic CA-repeat and CA-rich elements: a new class of regulators of mammalian alternative splicing. EMBO Journal 24 1988-1998.
Kozak M 1984 Point mutations close to the AUG initiator codon affect the efficiency of translation of rat preproinsulin in vivo. Nature 308 241-246.

Leung DW 2001 The structure and functions of human lysophosphatidic acid acyltransferases. Frontiers in Bioscience 6 d944-d953.

Li D, Yu L, Wu H, Shan Y, Guo J, Dang Y, Wei Y \& Zhao S 2003 Cloning and identification of the human LPAAT-zeta gene, a novel member of the lysophosphatidic acid acyltransferase family. Journal of Human Genetics $\mathbf{4 8}$ 438-442.

Lu B, Jiang YJ, Zhou Y, Xu FY, Hatch GM \& Choy PC 2005 Cloning and characterization of murine 1-acyl-sn-glycerol 3-phosphate acyltransferases and their regulation by PPARalpha in murine heart. Biochemical Journal 385 469-477.

McMaster CR \& Jackson TR 2004 Phospholipid synthesis in mammalian cells. In Lipid Metabolism and Membrane Biogenesis, pp 5-30. Ed. G Daum. Berlin Heidelberg: Springer-Verlag.

Nakanishi H, Shindou H, Hishikawa D, Harayama T, Ogasawara R, Suwabe A, Taguchi R \& Shimizu T 2006 Cloning and characterization of mouse lungtype acyl-CoA:lysophosphatidylcholine acyltransferase 1 (LPCAT1). Expression in alveolar type II cells and possible involvement in surfactant production. Journal of Biological Chemistry 281 20140-20147.

Rost B, Yachdav G \& Liu J 2004 The Predict Protein server. Nucleic Acids Research 32 W321-W326.

Slabas AR, Kroon JT, Scheirer TP, Gilroy JS, Hayman M, Rice DW, Turnbull AP, Rafferty JB, Fawcett T \& Simon WJ 2002 Squash glycerol-3-phosphate (1)-acyltransferase. Alteration of substrate selectivity and identification of arginine and lysine residues important in catalytic activity. Journal of Biological Chemistry 277 43918-43923.

Tamada T, Feese MD, Ferri SR, Kato Y, Yajima R, Toguri T \& Kuroki R 2004 Substrate recognition and selectivity of plant glycerol-3-phosphate acyltransferases (GPATs) from Cucurbita moscata and Spinacea oleracea. Acta Crystallographica. Section D. Biological Crystallography 60 13-21.

Turnbull AP, Rafferty JB, Sedelnikova SE, Slabas AR, Schierer TP, Kroon JT, Nishida I, Murata N, Simon JW \& Rice DW 2001a Crystallization and preliminary X-ray analysis of the glycerol-3-phosphate 1-acyltransferase from squash (Cucurbita moschata). Acta Crystallographica. Section D. Biological Crystallography $\mathbf{5 7}$ 451-453.

Turnbull AP, Rafferty JB, Sedelnikova SE, Slabas AR, Schierer TP, Kroon JT, Simon JW, Fawcett T, Nishida I, Murata N et al. $2001 b$ Analysis of the structure, substrate specificity, and mechanism of squash glycerol-3phosphate (1)-acyltransferase. Structure 9 347-353.

Vergnes L, Beigneux AP, Davis R, Watkins SM, Young SG \& Reue K 2006 Agpat6 deficiency causes subdermal lipodystrophy and resistance to obesity. Journal of Lipid Research 47 745-754.

Webber KO \& Hajra AK 1993 Purification of dihydroxyacetone phosphate acyltransferase from guinea pig liver peroxisomes. Archives of Biochemistry and Biophysics 300 88-97.

Weier D, Muller C, Gaspers C \& Frentzen M 2005 Characterisation of acyltransferases from Synechocystis sp. PCC6803. Biochemical and Biophysical Research Communications 334 1127-1134.

Ye GM, Chen C, Huang S, Han DD, Guo JH, Wan B \& Yu L 2005 Cloning and characterization a novel human 1-acyl-sn-glycerol-3-phosphate acyltransferase gene AGPAT7. DNA Sequence 16 386-390.

Received in final form 15 March 2007

Accepted 28 March 2007

Made available online as an Accepted Preprint 30 March 2007 